Research Article

\title{
Evaluating the Physical and Rheological Properties of Rejuvenated Styrene-Butadiene-Styrene-Modified Asphalt Binders
}

\author{
Xiaobing Chen $\mathbb{D}^{1},{ }^{1}$ Juntian Wang, ${ }^{1}$ Xiaorui Zhang $\mathbb{D}^{1},{ }^{1}$ Han Liu, ${ }^{2}$ Jinhu Tong, \\ and Ronglong Zhao ${ }^{1}$ \\ ${ }^{1}$ School of Transportation, Southeast University, Nanjing 211189, China \\ ${ }^{2}$ Municipal Transportation Design Branch, The Architectural Design and Research Institute of Zhejiang University, \\ Hangzhou 310028, China
}

Correspondence should be addressed to Xiaobing Chen; xbchen@seu.edu.cn and Xiaorui Zhang; zxr@seu.edu.cn

Received 30 May 2020; Revised 19 July 2020; Accepted 1 August 2020; Published 28 August 2020

Guest Editor: Zhen Leng

Copyright ( $\odot 2020$ Xiaobing Chen et al. This is an open access article distributed under the Creative Commons Attribution License, which permits unrestricted use, distribution, and reproduction in any medium, provided the original work is properly cited.

To evaluate the physical and rheological properties of rejuvenated styrene-butadiene-styrene-modified asphalt (SBSMA) binders designed for rapid in-place pavement recycling, an aged SBSMA binder was rejuvenated with three rejuvenators (i.e., Types I, II, and III) in different dosages. The physical properties of rejuvenated SBSMA were obtained to determine the optimal type and dosage of rejuvenators for the first and second rejuvenation. Performance grade (PG) tests, multiple stress creep recovery (MSCR) tests, and linear amplitude sweep (LAS) tests were conducted to measure the rheological properties using the dynamic shear rheometer (DSR) and bending beam rheometer (BBR). The results exhibited that the rejuvenators could soften the multiple aged binder and enhance its high- and low-temperature performance. The rejuvenation effect of rejuvenator Type I with the optimal dosage of $6 \sim 8 \%$ was the most appropriate for the first rejuvenation. The optimal dosage of the second rejuvenation was $10 \sim 12 \%$. The addition of rejuvenators decreased the rutting factor $\left(G^{*} / \sin \delta\right)$, creep stiffness $(S)$, delta $T_{c}\left(\Delta T_{c}\right)$ parameter, recovery response $(R)$, and yield stress of rejuvenated SBSMA. On the other hand, an increase in the rate of relaxation ( $m$-value), nonrecoverable creep compliance $\left(J_{\mathrm{nr}}\right)$, and yield strain of rejuvenated SBSMA was recorded. Overall, the study findings indicated an improvement in the elastic properties of rejuvenated SBSMA, which contributes to improving the rutting, thermal, and fatigue cracking resistance of asphalt binder and ultimately the response of asphalt pavements.

\section{Introduction}

Asphalt binder, which is a by-product of petroleum, is an essential material used in the construction of flexible pavements [1]. Styrene-butadiene-styrene (SBS) polymer, which is an elastomer thermoplastic polymer, is widely used as an asphalt binder modifier to enhance the high- and lowtemperature performance of asphalt mixtures [2]. However, aging and degradation of the SBS-modified asphalt (SBSMA) binders under the actions of oxygen, sunlight, rainfall, and vehicle loading can detrimentally deteriorate the performance of asphalt mixtures and eventually lead to pavement failures $[3,4]$. The aging phenomenon usually encompasses some internal changes in the chemical composition of the asphalt binder that ultimately leads to changes in the overall structural integrity of the asphalt mixture. For instance, because of the oxidation of the naphthalene aromatics and the polar aromatics, the ratio of asphaltene to maltene of aged SBSMA tends to increase [5]. The aged asphalt binder usually turns into a gel-type asphalt binder that exhibits low ductility, high stiffness, and high thixotropy [6]. The aging of SBS-modified asphalt binder is a combination of asphalt phase oxidation and polymer phase degradation [7]. The chain scission reaction at polybutadiene (PB) segments plays a primary role in the thermooxidative degradation of SBS polymer [8]. The PB segments containing the unsaturated double carbon bonds $(\mathrm{C}=\mathrm{C})$ are easy targets to oxygen and degrade rapidly into smaller polymer chains under the effect of heat and ultraviolet light (UV) $[9,10]$. Because of increased modulus due to oxidation and low SBS modification, 
asphalt mixtures also tend to be brittle with a high propensity to thermal and fatigue cracking $[11,12]$.

Asphalt mixtures are self-healing materials. In other words, under certain energy conditions, the microcracks can be self-repaired [13]. To enhance (and expedite) this selfrepairing process, rejuvenators are often added to aged asphalt binders to soften them and make the rejuvenated asphalt binders more fluid so as to be able to infiltrate into and fill up the cracks [14]. Rapid in-place pavement recycling is a preventive maintenance technology based on spraying the rejuvenator onto the aged pavement surface to seal off the cracks and soften the asphalt binder. Compared with other asphalt pavement recycling technologies, Liu [15] asserts that rapid in-place pavement recycling technology is quick, time-efficient, and the most economical and effective solution for asphalt pavement preservation.

As reported in the literature, rejuvenators have the potential to recover and enhance the material properties and mechanical performances of aged SBSMA [16]. However, having and/or injecting an optimum amount of rejuvenator is one of the key aspects of achieving the desired material properties and enhanced performance characteristics [17]. Balanced rejuvenating design based on multicriteria evaluation has been used by many researchers to optimize the rutting, cracking, and fatigue performances of asphalt binders $[18,19]$. Koudelka et al. [20] used two rheological parameters: the Glower-Rowe (G-R) parameter obtained from the dynamic shear rheometer (DSR) tests and the delta $T_{c}\left(\Delta T_{c}\right)$ obtained from the bending beam rheometer (BBR) tests to determine the optimum dosages of recycling agents. Elkashef et al. [21] found that the extent of rejuvenation/ regeneration of the soybean-derived rejuvenator was more pronounced for the stiffer binders. Shen et al. [22] investigated the changes in molecular weights of crumb rubbermodified asphalt binders both after aging and after rejuvenation. The addition of rejuvenator was found to have reduced the macromolecular substances and increased the micromolecular substances of aged asphalt binders. Zaumanis et al. [23] proved that the recycled asphalt mixtures with six rejuvenators could ensure excellent rutting and cracking resistances while providing longer fatigue life. Cui et al. [24] found that the rejuvenator can alleviate the selfaggregation of asphaltenes but cannot completely restore the colloidal structure of the aged asphalt binders by the means of molecular dynamics (MD) simulations. The rejuvenator/ recycling agent could deagglomerate the oxidized asphaltenes, which led to a concurrent increase in the crossover modulus and crossover frequency of aged binder [25]. Xu et al. [26] studied the rejuvenator diffusion behavior and thermodynamic properties of asphalt binder using all-atom MD simulations.

Traditional grading parameters of asphalt binders such as penetration, softening point, and viscosity cannot fully reflect the viscoelasticity of asphalt binders. In particular, these parameters have been considered to be insufficient in characterizing the performances of asphalt binders at high temperatures [27]. Furthermore, the Superpave rutting parameter $G^{*} / \sin \delta$ has been reported to exhibit poor correlation with the rutting resistance of polymer-modified asphalt mixtures measured in the laboratory [28]. Multiple stress creep recovery (MSCR) test, developed by D'Angelo et al. [29], can more fundamentally represent the nonlinear viscoelastic behavior of asphalt binders over a range of high temperatures [30,31].

Similarly, the Superpave fatigue parameter, $G * / \sin \delta$, could not accurately estimate the maximum fatigue life of asphalt mixtures under nonlinear viscoelastic loading [32]. The viscoelastic continuum damage (VECD) theory is a novel approach used to characterize the fatigue behavior of viscoelastic materials. Linear amplitude sweep (LAS) test has been developed based on VECD theory and provides more reliable parameters to estimate and quantify the fatigue life of asphalt binders at varying stress levels [33, 34].

The primary aim of this study was to investigate the effects of rejuvenators on the physical and rheological performances of the aged and rejuvenated SBSMA. The optimal types and dosages of rejuvenators were determined based on multicriteria evaluation to provide a laboratory assessment framework for rapid in-place pavement recycling. Because the performance evaluation of rejuvenated asphalt binders is often limited to traditional grading parameters such as viscosity, penetration, and softening point, another aim of this study was to evaluate the rutting and fatigue characteristics of rejuvenated SBSMA through measurement and quantification of their rheological properties using the MSCR and LAS tests.

\section{Materials and Test Methods}

2.1. Asphalt Binders and Rejuvenators. The basic properties of the Shell SBS-modified asphalt binders are listed in Table 1 . The amount of SBS polymer incorporated in asphalt binder was $4.5 \%$. The rejuvenator was prepared with a heavy naphthenic base oil and the polymer-modified asphalt. The principal properties of three rejuvenators used, designated as Types I, II, and III, respectively, are similarly listed in Table 2. The samples of three rejuvenators are shown in Figure 1.

2.2. Laboratory Experimentation. Agings of the SBSMA were accomplished using the rolling thin-film oven test (RTFOT, aging at $163^{\circ} \mathrm{C}$ for $5 \mathrm{~h}$ ) and pressurized aging vessel test $\left(\mathrm{PAV}\right.$, aging at $100^{\circ} \mathrm{C}$ for $20 \mathrm{~h}$ under $2.1 \mathrm{MPa}$ of air pressure) according to ASTM D2872 and ASTM D6521, respectively. RTFOT was used to simulate the short-term aging of the SBSMA at the construction stage such as production, mixing, transporting, and paving processes. PAV was employed to simulate the long-term field aging of the SBSMA at the service stage.

The virgin SBSMA was aged by RTFOT and PAV to obtain the first aged SBSMA. Then the first aged SBSMA was blended with the three rejuvenators at a mixing temperature $140 \sim 160^{\circ} \mathrm{C}$ for $30 \mathrm{~min}$ to prepare the first rejuvenated SBSMA. The rejuvenator at dosages/contents was $2 \%, 4 \%$, $6 \%, 8 \%$, and $10 \%$, respectively, by weight of aged asphalt binders.

Because there is no heating applied on the aged asphalt mixtures through the rapid in-place pavement recycling, the 
TABLE 1: The basic properties of SBS-modified asphalt binders.

\begin{tabular}{|c|c|c|c|}
\hline Properties & Methods & Limits & Values \\
\hline \multicolumn{4}{|l|}{ Virgin asphalt binders } \\
\hline Penetration at $25^{\circ} \mathrm{C}(0.1 \mathrm{~mm})$ & ASTM D5 & $40 \sim 60$ & 51 \\
\hline Softening point $\left({ }^{\circ} \mathrm{C}\right)$ & ASTM D36 & $\geq 60$ & 79 \\
\hline Ductility at $5^{\circ} \mathrm{C}(\mathrm{cm})$ & ASTM D113 & $\geq 20$ & 26 \\
\hline Elastic recovery at $25^{\circ} \mathrm{C}(\%)$ & $\begin{array}{l}\text { ASTM } \\
\text { D6084 }\end{array}$ & $\geq 70$ & 88 \\
\hline $\begin{array}{l}\text { Storage stability, } \Delta \text { Soft. Points, } \\
48 \mathrm{~h}\left({ }^{\circ} \mathrm{C}\right)\end{array}$ & $\begin{array}{l}\text { ASTM } \\
\text { D5976 }\end{array}$ & $\leq 2.5$ & 1.5 \\
\hline Solubility in trichloroethane (\%) & $\begin{array}{l}\text { ASTM } \\
\text { D2042 }\end{array}$ & $\geq 99$ & 99.5 \\
\hline Flash point $\mathrm{COC}\left({ }^{\circ} \mathrm{C}\right)$ & ASTM D92 & $\geq 230$ & 280 \\
\hline Viscosity at $135^{\circ} \mathrm{C}(\mathrm{Pa} \cdot \mathrm{s})$ & $\begin{array}{l}\text { ASTM } \\
\text { D4402 }\end{array}$ & $\leq 3$ & 1.5 \\
\hline \multicolumn{4}{|l|}{ RTFOT residues } \\
\hline Mass loss (\%) & $\begin{array}{l}\text { ASTM } \\
\text { D2872 }\end{array}$ & $\leq 0.6$ & 0.2 \\
\hline Penetration ratio at $25^{\circ} \mathrm{C}(\%)$ & ASTM D5 & $\geq 65$ & 69 \\
\hline Ductility at $5^{\circ} \mathrm{C}(\mathrm{cm})$ & ASTM D113 & $\geq 15$ & 17 \\
\hline
\end{tabular}

second aging of SBSMA is a long-term aging. The first rejuvenated SBSMA with optimal types and dosages of rejuvenators $(I+6 \%, I+8 \%, I I+6 \%$, and $I I+8 \%)$ was aged by $\mathrm{PAV}$ and then rejuvenated with rejuvenators Type I and Type II to obtain the second rejuvenated SBSMA. The rejuvenators at dosage increments were $0 \%, 2 \%, 4 \%$, and $6 \%$. Thereafter, the aged and rejuvenated SBSMA were tested to evaluate and quantify their physical and rheological properties (Figure 2).

2.3. Physical Property Tests. Physical properties of the aged and rejuvenated SBSMA, including penetration $\left(25^{\circ} \mathrm{C}\right)$, softening point, and ductility $\left(5^{\circ} \mathrm{C}\right)$, were tested as per ASTM D5, ASTM D36, and ASTM D113, respectively.

2.4. Rheological Property Tests. Dynamic rheological properties of the virgin, aged, and rejuvenated SBSMA were performed using the DSR (Discovery HR-1, TA Instruments, USA) and the BBR (TE-BBR, Cannon, USA).

2.4.1. Dynamic Shear Rheometer Test. Temperature sweep tests were carried out using DSR at the strain-controlled mode. The temperature range was $64 \sim 82^{\circ} \mathrm{C}$ with increment of $6^{\circ} \mathrm{C}$. The asphalt binder specimens were molded to a diameter of $25 \mathrm{~mm}$ by $1 \mathrm{~mm}$ thick. High-temperature PG was determined based on the established rutting factor criteria $\left(G^{*} / \sin \delta=2.2 \mathrm{kPa}\right)$ as per ASTM D6373.

2.4.2. Bending Beam Rheometer Test. The low-temperature $\mathrm{PG}$ was estimated using the BBR at two test temperatures $\left(-12^{\circ} \mathrm{C}\right.$ and $\left.-18^{\circ} \mathrm{C}\right)$. Low-temperature PG was determined based on the thermal cracking criteria $(S(t)=300 \mathrm{MPa}, m$ value $=0.3)$ in accordance with ASTM D6373. The $S(t)$ and $m$-value were estimated using equations (1) and (2) as per ASTM D6648. The $\Delta T_{c}$ parameter was developed by Anderson et al. [35] to evaluate age-related cracking potential. Delta $T_{c}\left(\Delta T_{c}\right)$ parameter, described as in equation (5), is defined as the numerical difference between two low continuous grading temperatures obtained from the BBR stiffness and $m$-value criteria [36]:

$$
\begin{aligned}
S(t) & =\frac{P L^{3}}{4 b h^{3} \delta(t)}, \\
m(t) & =\left|\frac{\operatorname{dlog} S(t)}{\operatorname{dlog}(t)}\right|, \\
T_{c, S} & =T_{1}+\left(\frac{\left(T_{1}-T_{2}\right) \times\left(\log 300-\log S_{1}\right)}{\log S_{1}-\log S_{2}}\right)-10, \\
T_{c, m} & =T_{1}+\left(\frac{\left(T_{1}-T_{2}\right) \times\left(0.3-m_{1}\right)}{m_{1}-m_{2}}\right)-10, \\
\Delta T_{c} & =T_{c, S}-T_{c, m},
\end{aligned}
$$

where $S(t)$ is the creep stiffness at loading time $t(\mathrm{MPa}) ; m(t)$ is the rate of relaxation, $m$-value, at loading time $t$; $P$ is the applied load $(\mathrm{N}) ; L$ is the span length $(\mathrm{mm}) ; b$ is the width of the asphalt binder beam (mm); $h$ is the depth of the asphalt binder beam $(\mathrm{mm}) ; \delta(t)$ is the deflection of the asphalt binder beam at time $t(\mathrm{~mm}) ; S_{i}$ is the creep stiffness at temperature $T_{i}$, $(\mathrm{MPa}) ; m_{i}$ is the rate of relaxation at temperature $T_{i} ; T_{c, S}$ is the critical temperature where $S=300 \mathrm{MPa}\left({ }^{\circ} \mathrm{C}\right) ; T_{c, m}$ is the critical temperature where $m=0.3\left({ }^{\circ} \mathrm{C}\right)$; and $\Delta T_{c}$ is the numerical difference between $T_{c, S}$ and $T_{c, m}\left({ }^{\circ} \mathrm{C}\right)$.

2.4.3. Multiple Stress Creep Recovery (MSCR) Test. The MSCR tests were performed at $70^{\circ} \mathrm{C}$ in accordance with the ASTM D7405 test procedure. Two loading stress levels of $0.1 \mathrm{kPa}$ and $3.2 \mathrm{kPa}$ were used. Each stress level had 10 repeated cycles with creep stage of 1 s-loading and recovery stage of $9 \mathrm{~s}$-unloading. The total test time for one specimen was $200 \mathrm{~s}$. In this study, the MSCR test was used to characterize the high-temperature rheological behavior and stressrelated rutting resistance of rejuvenated SBSMA. Percent recovery $(R)$ parameter and nonrecoverable creep compliance $\left(J_{\mathrm{nr}}\right)$ were used to characterize the recovery properties and high-temperature performance of asphalt binders. The stress sensitivity index $\left(J_{\text {nr-diff }}\right)$, defined as the percentage difference of the $J_{\mathrm{nr}}$ at two stress levels, was used to evaluate the stress sensitivity of the rejuvenated SBSMA to traffic loading.

2.4.4. Linear Amplitude Sweep (LAS) Test. The LAS test was used to evaluate the fatigue behavior of the rejuvenated SBSMA. The asphalt binder specimens were molded to a diameter of $8 \mathrm{~mm}$ by $2 \mathrm{~mm}$ thick. In this study, the LAS test was conducted at $25^{\circ} \mathrm{C}$ in accordance with the AASHTO TP101 test procedure. The procedure of the LAS test was comprised of two steps. First, the frequency sweep test with a frequency range of $0.1 \sim 30 \mathrm{~Hz}$ was performed at a low strain level of $0.1 \%$ to obtain the undamaged property of specimen $(\alpha)$ and fatigue parameter $A$. Then, the amplitude sweep test in strain-controlled mode was conducted at $10 \mathrm{~Hz}$ for $300 \mathrm{~s}$. 
TABLE 2: The principal properties of rejuvenators Types I, II, and III.

\begin{tabular}{|c|c|c|c|c|}
\hline \multirow{2}{*}{ Properties } & \multirow{2}{*}{ Methods } & \multicolumn{3}{|c|}{ Rejuvenators } \\
\hline & & Type I & Type II & Type III \\
\hline \multicolumn{5}{|l|}{ Test on emulsions } \\
\hline Viscosity at $25^{\circ} \mathrm{C}$ (SFS) & ASTM D7496 & $25 \sim 150$ & $20 \sim 60$ & $25 \sim 150$ \\
\hline Residue (\%) & ASTM D6934 & $>64$ & $60 \sim 65$ & $>64$ \\
\hline Miscibility test & ASTM D6999 & Nonseparation & Nonseparation & Nonseparation \\
\hline Sieve test $(\%)$ & ASTM D6933 & $<0.1$ & $<0.1$ & $<0.1$ \\
\hline Particle charge test & ASTM D7402 & Positive & Positive & Positive \\
\hline Cement mixing test (\%) & ASTM D6935 & $<2$ & $<2$ & $<2$ \\
\hline Pumping stability ${ }^{1}$ & & Pass & Pass & Pass \\
\hline \multicolumn{5}{|l|}{ Tests on residue from distillation test } \\
\hline Viscosity at $60^{\circ} \mathrm{C}(\mathrm{cSt})$ & ASTM D2170 & $1000 \sim 4000$ & $200 \sim 500$ & $1000 \sim 4000$ \\
\hline Asphaltenes (\%) & ASTM D2007 & $<11.2$ & $2 \sim 4$ & $<11$ \\
\hline Maltene distribution ratio $\left(\mathrm{PC}+A_{1}\right) /\left(S+A_{2}\right)^{2}$ & ASTM D2007 & $0.8 \sim 1.5$ & $0.5 \sim 0.9$ & $0.7 \sim 1.1$ \\
\hline $\mathrm{PC} / S$ ratio $^{2}$ & ASTM D2007 & $>1.2$ & $>1.2$ & $>0.5$ \\
\hline
\end{tabular}

Note: 1 : pumping stability is tested by pumping $475 \mathrm{~mL}$ of rejuvenators, diluted one part concentrate to one part water, at $25^{\circ} \mathrm{C}$, through a $6 \mathrm{~mm}$ gear pump operating $1750 \mathrm{rpm}$ for 10 minutes with no significant separation or coagulation. 2: PC is a polar compound; $A_{1}$ is the first acidaffins; $A_{2}$ is the second acidaffins; $S$ is the saturated hydrocarbons.

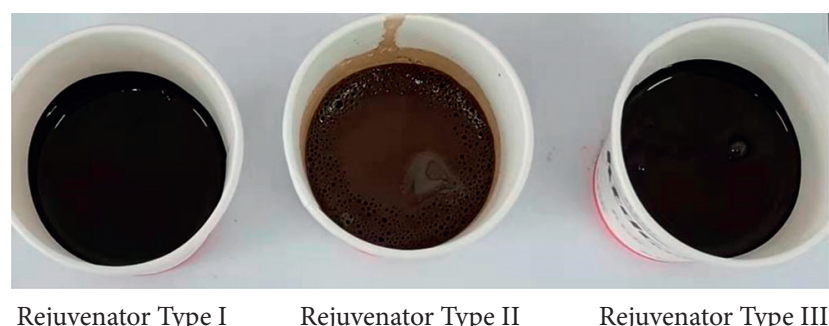

Figure 1: Samples of rejuvenators Types I, II, and III.

The amplitude of sine wave load form increased linearly from $0.1 \%$ to $30 \%$. The LAS test data was processed and analyzed using a VECD model approach to determine the fatigue parameters $A$ and $B$. Given the fundamental nature of these fatigue parameters, the fatigue life of the asphalt binder can be estimated through the fatigue model given in

$$
\begin{aligned}
N_{\mathrm{f}} & =A\left(\gamma_{\max }\right)^{-B}, \\
A & =\frac{f\left(D_{\mathrm{f}}\right)^{\left(1+\left(1-C_{2}\right) \alpha\right)}}{\left(1+\left(1-C_{2}\right) \alpha\right) \times\left(\pi C_{1} C_{2}\right)^{\alpha}}, \\
B & =-2 \alpha,
\end{aligned}
$$

where $N_{\mathrm{f}}$ is the fatigue life; $\gamma_{\max }$ is the estimated maximum strain (\%); $A$ and $B$ are the fatigue parameters; $f$ is the loading frequency $(\mathrm{Hz}) ; D_{\mathrm{f}}$ is the failure point at a $35 \%$ reduction in the initial specimen modulus; $\alpha$ is the undamaged property of the specimen; and $C_{1}$ and $C_{2}$ are the fitting factors of the power-law model.

\section{Test Results, Analysis, and Discussions}

3.1. Physical Properties of Rejuvenated SBSMA. Figure 3 shows the physical properties of the first and second rejuvenated SBSMA with different types and dosages of rejuvenators.
3.1.1. The First Rejuvenated SBSMA. With the increase of the rejuvenator dosage, the penetration and ductility of rejuvenated SBSMA increased, while the softening point decreased (Figures 3(a), 3(c), and 3(e)). When the rejuvenator dosage was $0 \sim 4 \%$, the penetration improvement of aged SBSMA was Type III > Type I > Type II. When the rejuvenator dosage was $4 \sim 10 \%$, the efficiency of Type III on penetration improvement was weaker than that of Type I and Type II (Figure 3(a)). A small amount of rejuvenator could obviously reduce the softening point of aged SBSMA, but the further addition of rejuvenator had not a significant effect as before. Compared with Type I and Type III, Type II had a weaker effect on reducing the softening point (Figure 3(c)). For each $1 \%$ rejuvenator added to the aged SBSMA, the ductility of the rejuvenated SBSMA could be increased by about $1 \mathrm{~cm}$. The ductility improvement of aged SBSMA was Type I $\approx$ Type II > Type III (Figure 3(e)). Therefore, the asphalt blends with rejuvenators Type I and Type II exhibited improved low-temperature crack resistance. The rejuvenators containing the maltenes could effectively reduce the consistency and restore the temperature sensitivity of aged SBSMA. The physical properties of the first rejuvenated SBSMA with 6 8\% rejuvenators were closest to those of RTFOT residues. The rejuvenation effect of Type I and Type II with the optimal dosage of $6 \sim 8 \%$ was superior to that of Type III for the first rejuvenation.

3.1.2. The Second Rejuvenated SBSMA. After the second aging of SBSMA, the addition of rejuvenators could still rejuvenate the second aged SBSMA and improve the physical properties of the second rejuvenated SBSMA (Figures 3(b), $3(\mathrm{~d})$, and 3(f)). The physical properties of the second rejuvenated SBSMA were linearly related to the increments of rejuvenator dosages. However, the second rejuvenation was more difficult than the first rejuvenation. In order to recover the performance loss of the second aging, the second rejuvenation of SBSMA needed to increase the dosage of rejuvenator. When the rejuvenator dosage was increased by $4 \%$, 


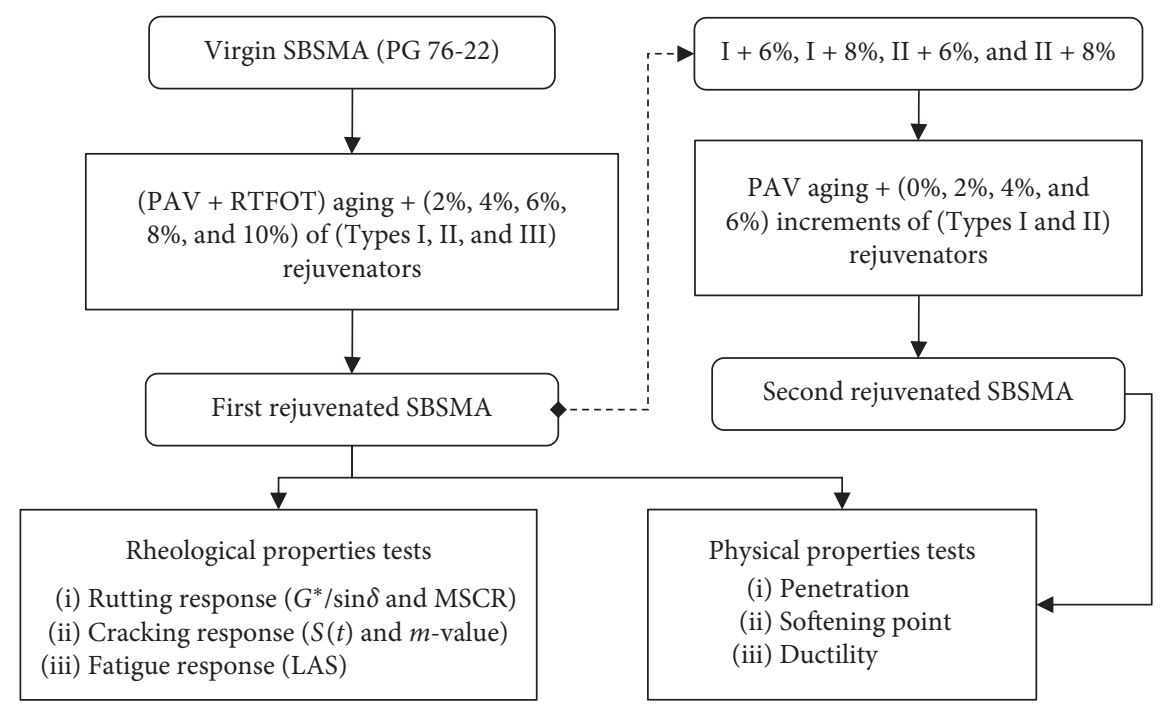

FIgURE 2: Flowchart of experimental plan.

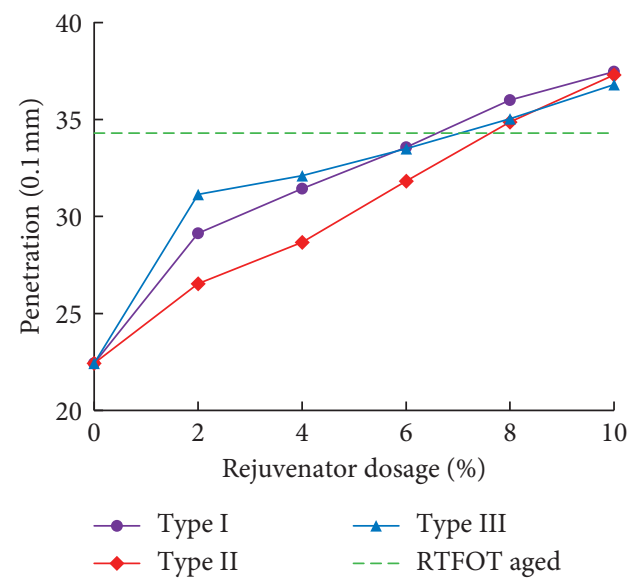

(a)

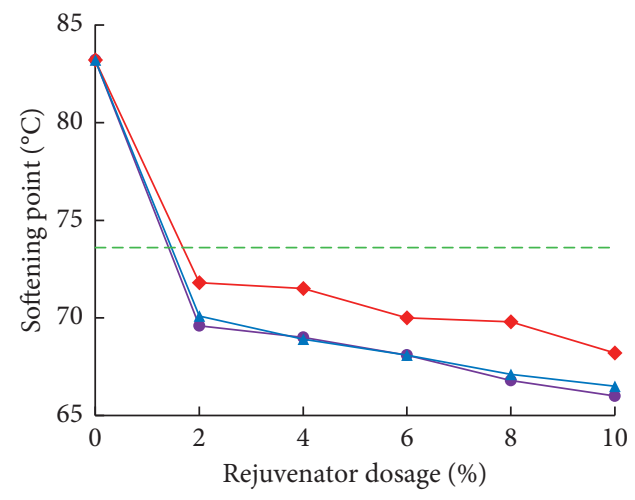

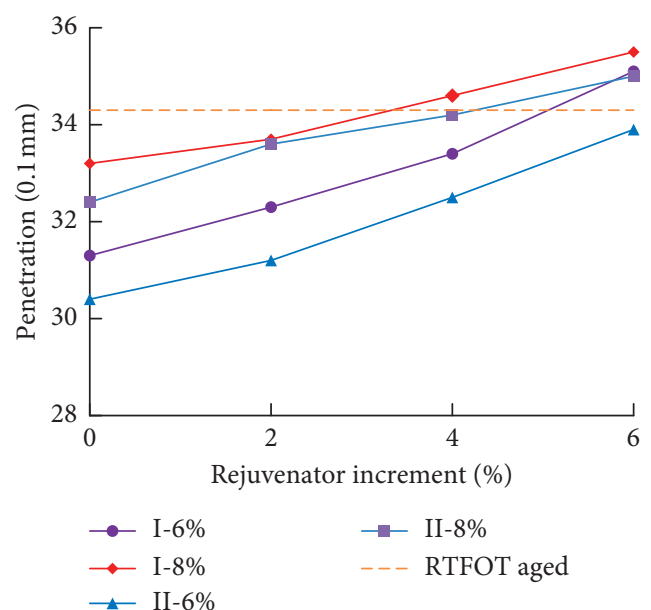

(b)

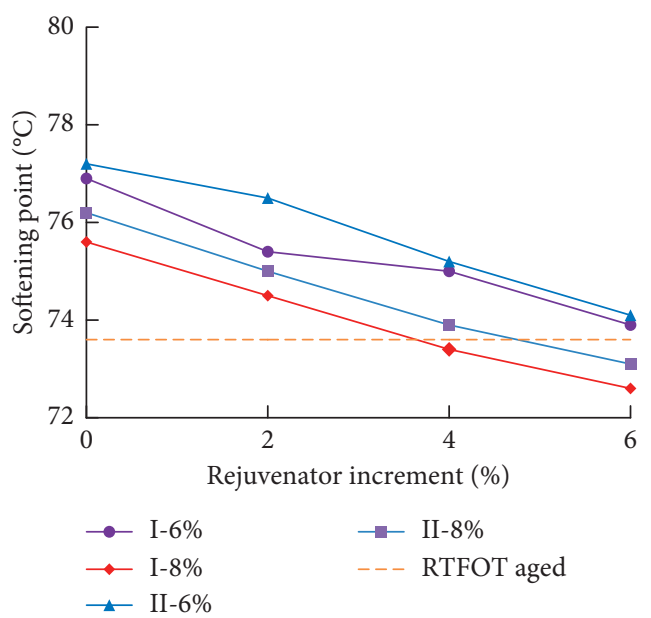

(d)

(c)

FIgURE 3: Continued. 


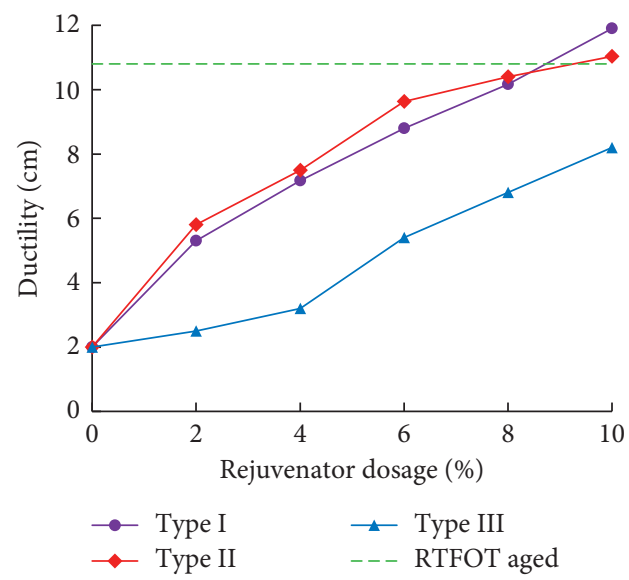

(e)

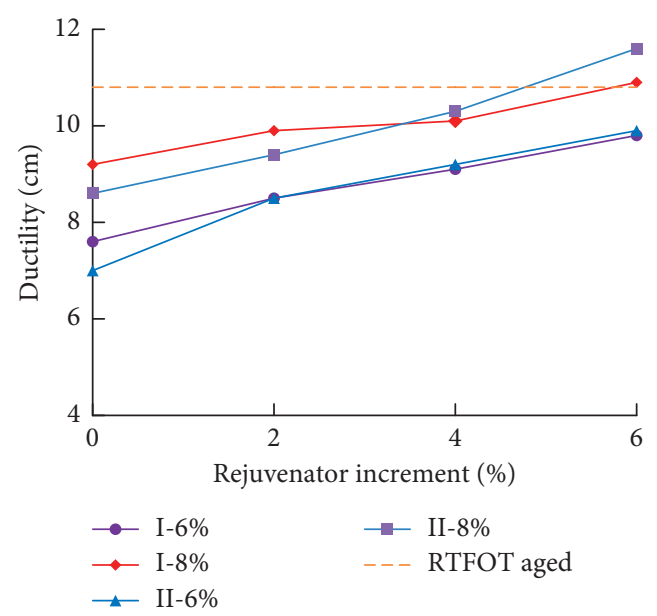

(f)

FIGURe 3: Physical properties of the first and second rejuvenated SBSMA. The first rejuvenation (a, c, e); the second rejuvenation (b, d, f).

the effects of the first rejuvenation could be achieved in the second rejuvenation, suggesting the feasibility of multiple rejuvenation of aged SBSMA. Thus, the optimal rejuvenator dosage of the second rejuvenation was $10 \sim 12 \%$.

\subsection{Rheological Properties of Rejuvenated SBSMA}

3.2.1. Dynamic Shear Rheometer Test. Figure 4 shows the rutting factors $\left(G^{*} / \sin \delta\right)$ of the rejuvenated SBSMA with different dosages of three types of rejuvenators. After PAV aging, the rutting factors of SBSMA increased, indicating that the aging strengthened the elastic behavior and the rutting resistance of the virgin SBSMA. The rutting factors decreased with the increases of the rejuvenator dosages and the temperatures, which revealed that the rejuvenators could effectively soften the aged SBSMA and decrease the deformation resistance of the asphalt binders. However, the rutting factors of rejuvenated SBSMA should be higher than those of virgin SBSMA. It is suggested that the dosage of rejuvenators should be controlled within $8 \%$. Under the same rejuvenator dosage $(6 \%)$, the rejuvenation efficiency of the rejuvenators was Type I $\approx$ Type III > Type II. The maltene distribution ratio of Types I and III was larger than that of Type II. The rejuvenation efficiency of rejuvenator depended on the ability to restore the original chemical ratio of the asphalt binder components. The rutting factor of the rejuvenated SBSMA with 6\% rejuvenator Type I was basically consistent with that of the virgin SBSMA.

3.2.2. Bending Beam Rheometer Test. Figures 5(a) and 5(b) illustrate the creep stiffness $(S(t))$ and the rate of relaxation ( $m$-value) of the different rejuvenated SBSMA. The $S(t)$ value and $m$-value reflect the flexibility of asphalt binders at lowtemperature. In general, the asphalt binder with lower $S(t)$ and higher $m$-value have improved low-temperature crack resistance potential. After PAV aging, an increase in $S(t)$ value and a decrease in the $m$-value weaken the resistance to slow crack growth of SBSMA, increasing the risks of thermal cracking. In general, the low-temperature performance of asphalt binder is related to the proportion of larger molecules. During the aging process, the light components of asphalt binder volatilized, and the polymerization of small molecules increased the proportion of large molecules [22]. The additions of rejuvenators could replenish the small molecules, which were lost in the aging process, and adjust the proportions of asphalt components, thus enhancing the crack resistance of asphalt binder. The additions of rejuvenators decreased the $S(t)$ value and increased the $m$-value of aged SBSMA, indicating that the rejuvenators could recover the low-temperature elasticity and improve the crack resistance of aged SBSMA. Among three rejuvenators, the SBSMA rejuvenated with rejuvenators Type I and Type II had a higher $S(t)$ value and a lower $m$-value, indicating that these asphalt blends had more potential to resist thermal cracking and age-related embrittlement distresses.

Figure 5(c) demonstrates that $\Delta T_{c}$ values of rejuvenated asphalt binder are quite different for different types and dosages of rejuvenators. Li et al. [37] have suggested limiting $\Delta T_{c}$ at $-5^{\circ} \mathrm{C}$ to avoid nonload related cracking due to poor relaxation properties of asphalt binders. The $\Delta T_{c}$ values of PAV aged and $\mathrm{I}-10 \%$ binders were $-8.7^{\circ} \mathrm{C}$ and $-5.7^{\circ} \mathrm{C}$, respectively, failing to meet minimum $\Delta T_{c}$ criteria. All binders were $m$-controlled with negative $\Delta T_{c}$ values. More $m$-controlled binder might tend to thixotropically harden and exhibit brittle behavior when exposed to thermal stresses. Rejuvenated binders tended to have lowly negative $\Delta T_{c}$ values. For all rejuvenated binders, a positive increase in the value of $\Delta T_{c}$ indicated an enhancement in the stress relaxation ability and less age-related cracking potential of the rejuvenated binders. Excessive dosage of rejuvenator Type I should be avoided to ensure the durability of asphalt binder.

3.2.3. Superpave Performance Grade. Superpave PG of the different rejuvenated SBSMA is provided in Figure 6. The high failure temperature of the rejuvenated SBSMA 


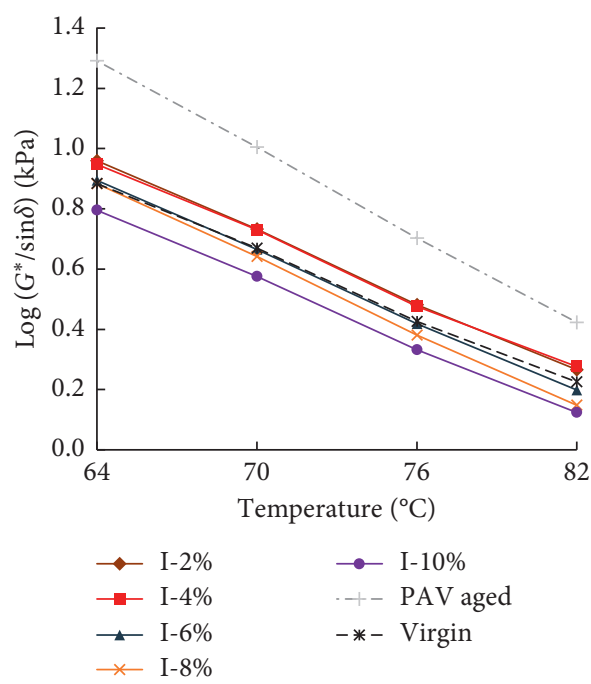

(a)

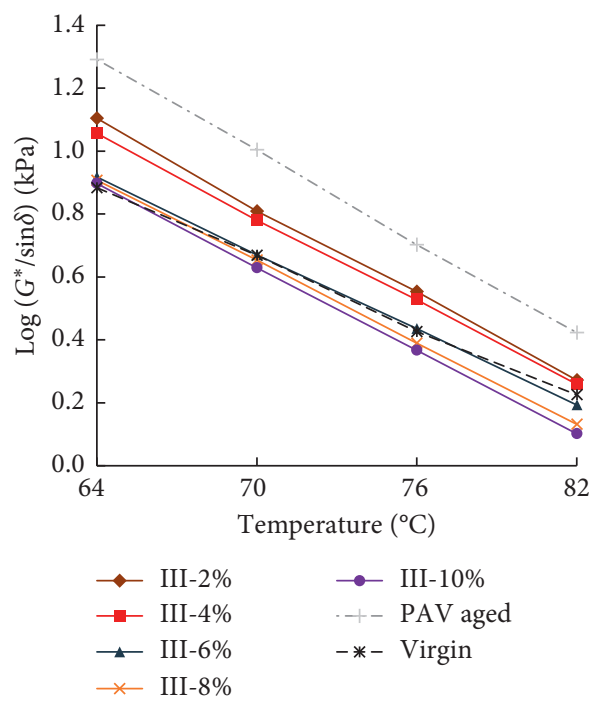

(c)

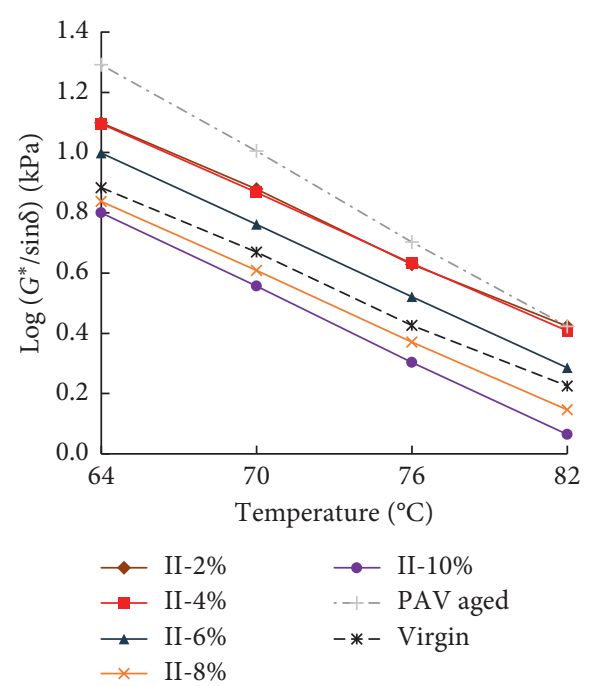

(b)

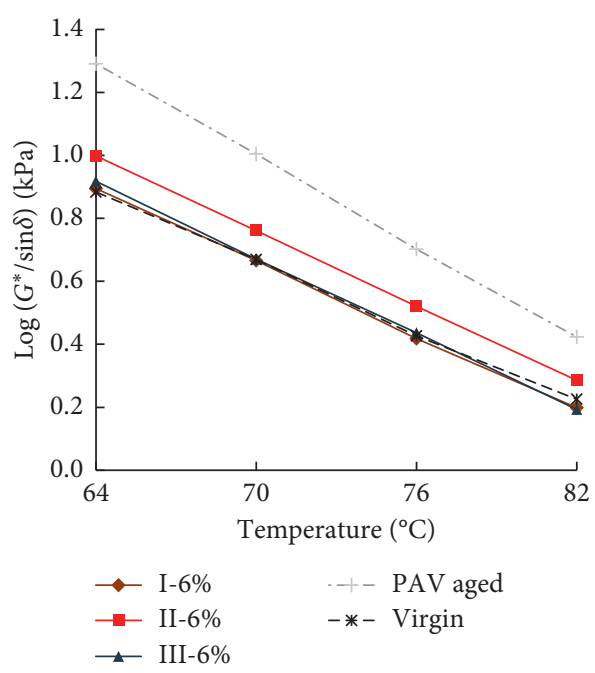

(d)

FIgURE 4: Variations of rutting factors with the types and dosages of rejuvenators. (a) Rejuvenator Type I; (b) rejuvenator Type II; (c) rejuvenator Type III; (d) rejuvenator dosage is $6 \%$.

decreased with the increases of the rejuvenator dosages, indicating the softening and regenerating effects of rejuvenators to the aged SBSMA. Similarly, the critical low failure temperature decreased with the additions of rejuvenators exhibited improvement in the flexibility of SBSMA. Rejuvenators that had affinity for various fractions of the asphalt binder would enhance the high- and low-temperature performances of the aged binder through restoration of the original binder asphaltenes-to-maltenes ratio. The addition of $6 \sim 8 \%$, by weight of aged SBSMA, of rejuvenator Type I could achieve the target PG of virgin SBSMA, PG 7622.

3.2.4. Rutting Performance Based on the MSCR Test. Figures 7 (a) and 7(b) show the recovery responses of rejuvenated SBSMA with different types and contents of the rejuvenators at the stress levels of $0.1 \mathrm{kPa}$ and $3.2 \mathrm{kPa}$, respectively. A decrease in the recovery response $(R)$ and an increase in the nonrecoverable creep compliance $\left(J_{\mathrm{nr}}\right)$ were observed in the rejuvenated asphalt binder suggesting a significant rejuvenation of the asphalt binders. However, as the rejuvenator dosage increased, the $R$ value decreased while the $J_{\text {nr }}$ value increased indicating a decay in the rutting resistance characteristics. A slight fluctuation of $R$ value indicated the limited effects of rejuvenators on the recovery performance of the rejuvenated SBSMA. In general, the blends with $4 \sim 6 \%$ rejuvenators exhibited good stress and strain recovery performance. Additionally, the changes in the $J_{\mathrm{nr} 3.2}$ value (with a high stress level) were higher than the $J_{\text {nr0.1 }}$ value (with a low stress level), implying severe rutting risks of rejuvenated asphalt binders under heavy traffic loading, particularly in elevated temperature environments [12]. 


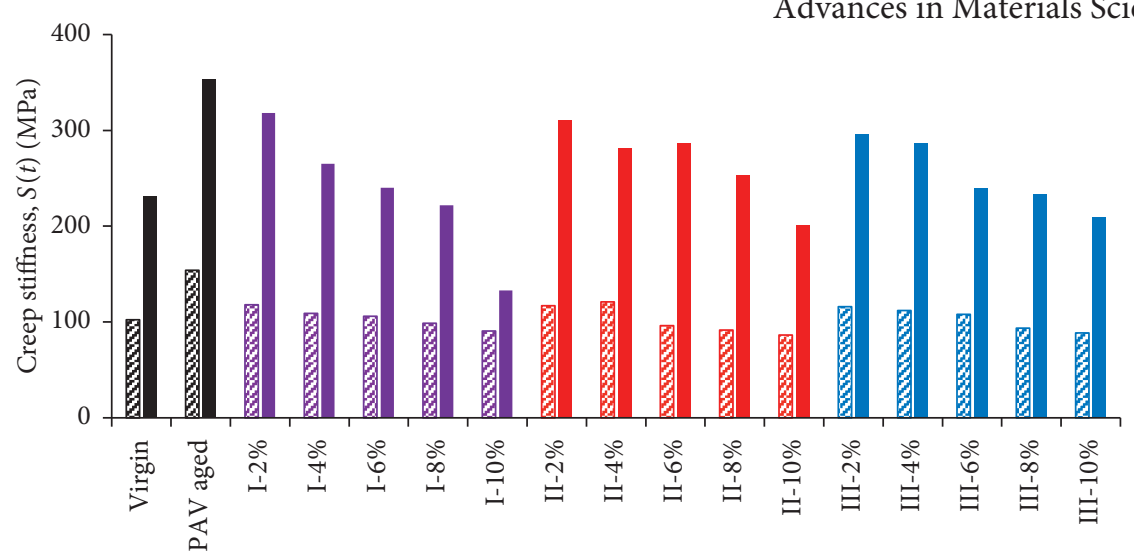

Binder types

a $-12^{\circ} \mathrm{C}$

- $-18^{\circ} \mathrm{C}$

(a)

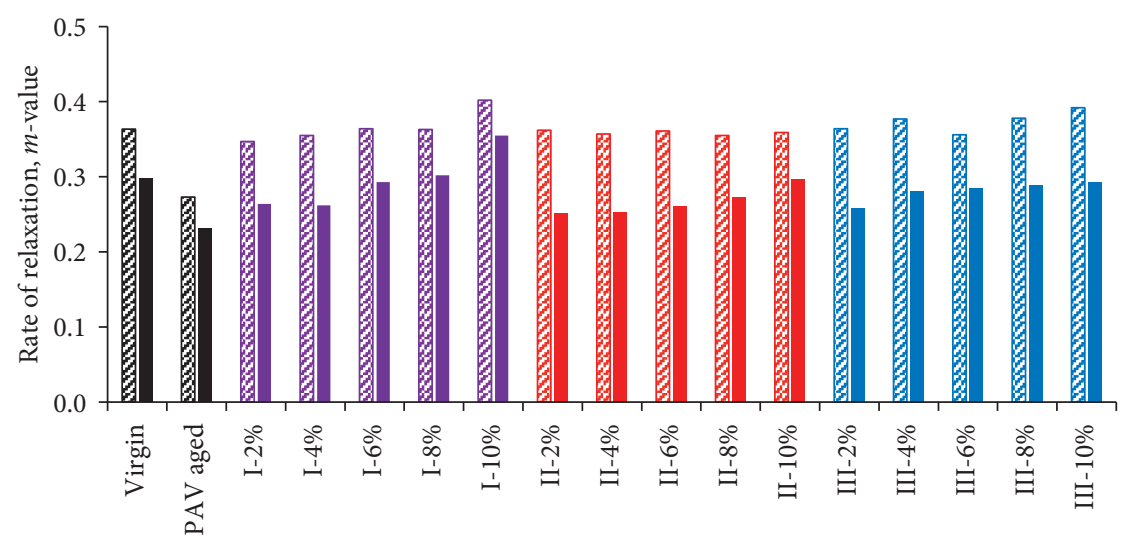

Binder types

ป $-12^{\circ} \mathrm{C}$

- $-18^{\circ} \mathrm{C}$

(b)

Binder types

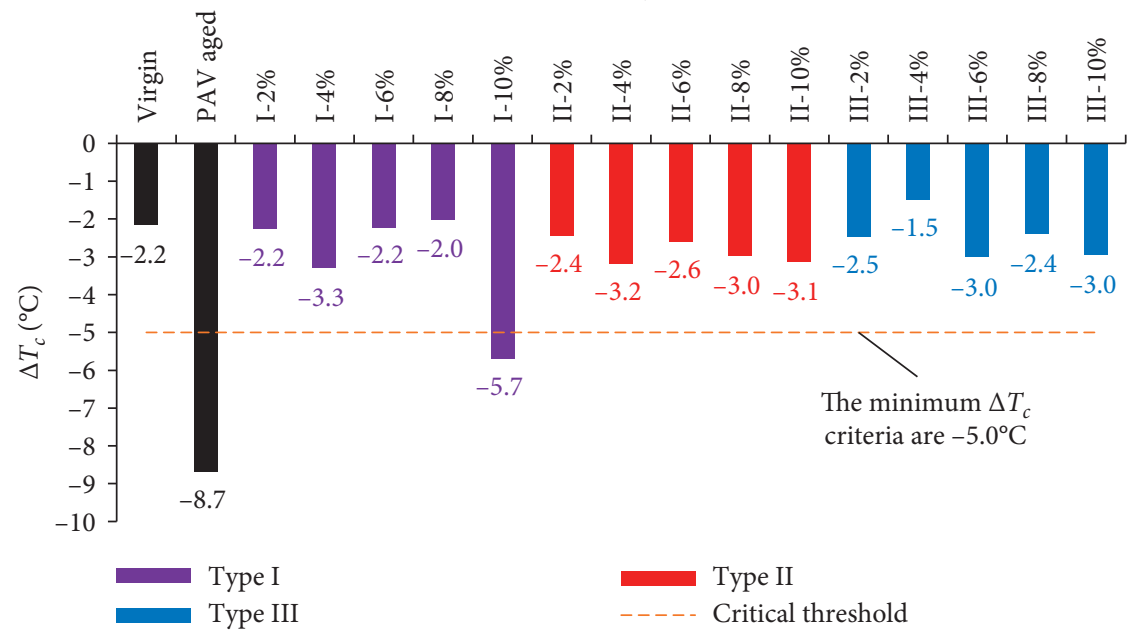

(c)

FIGURE 5: Effects of the types and dosages of rejuvenators on (a) creep stiffness $(S(t))$; (b) rate of relaxation ( $m$-value); (c) difference of BBR creep or $m$ critical temperature, delta $T_{c}\left(\Delta T_{c}\right)$. 


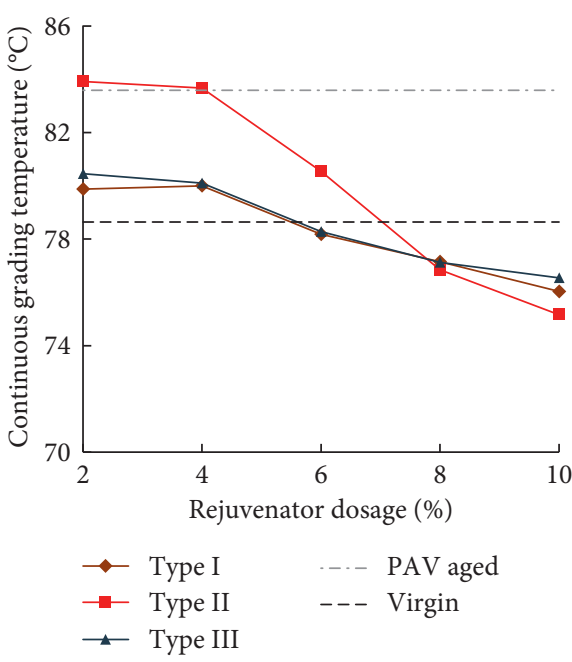

(a)

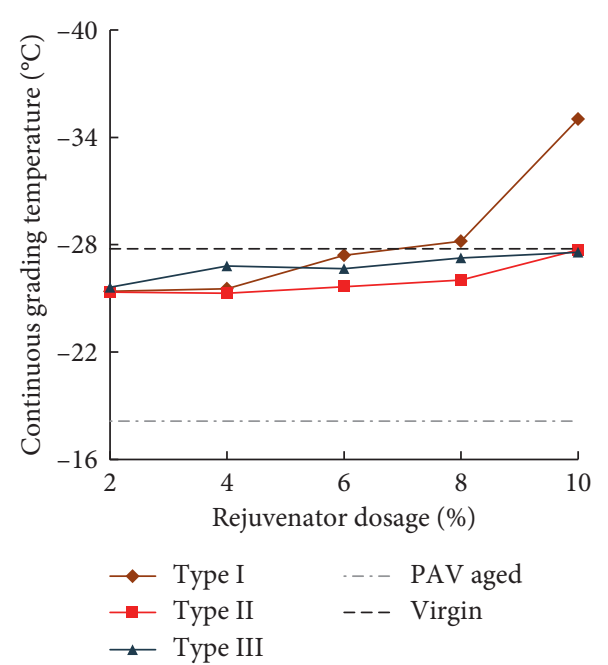

(b)

Figure 6: Superpave PG of different rejuvenated SBSMA. (a) High-temperature continuous grade; (b) low-temperature continuous grade.

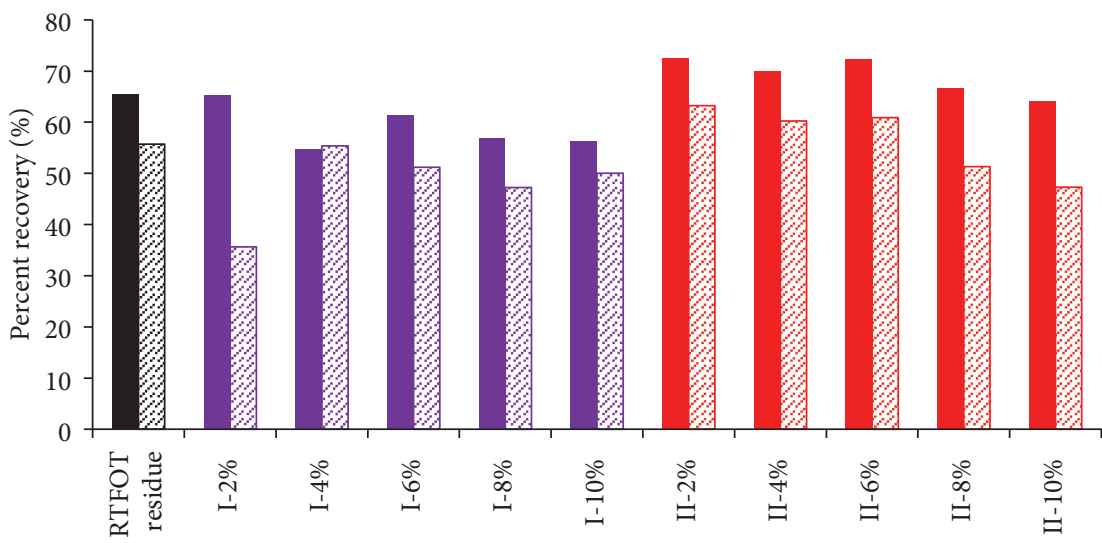

Binder types

- $R_{01}$

2a $R_{3.2}$

(a)

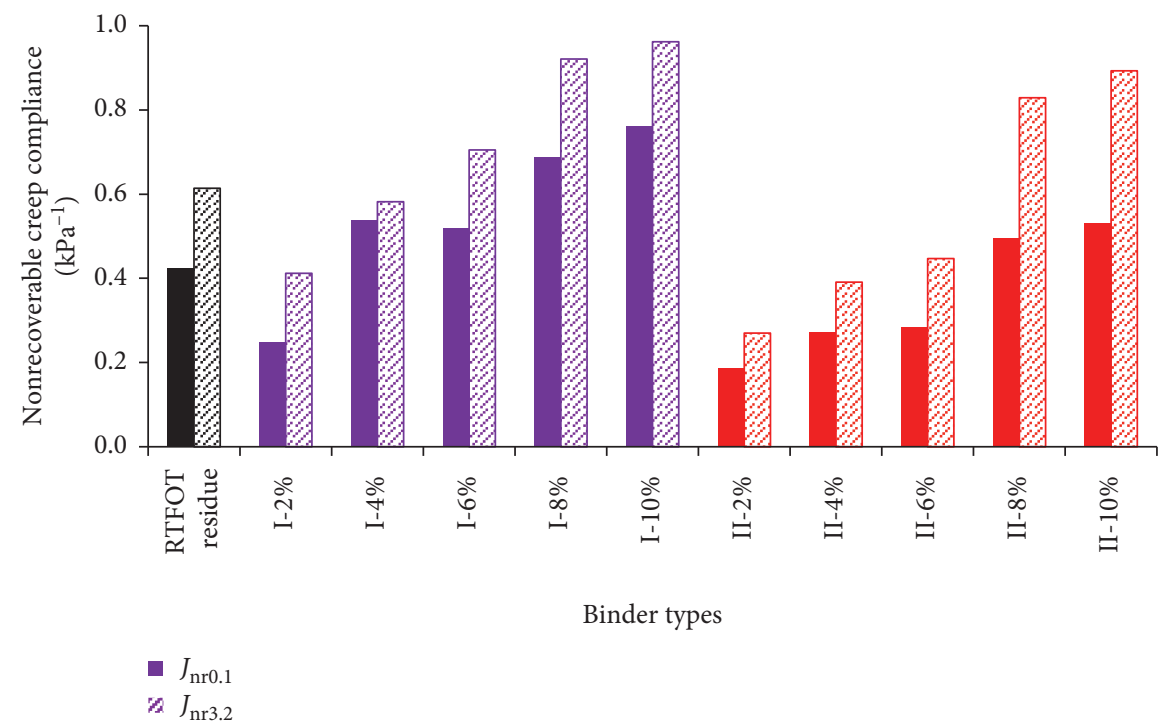

(b)

Figure 7: Continued. 


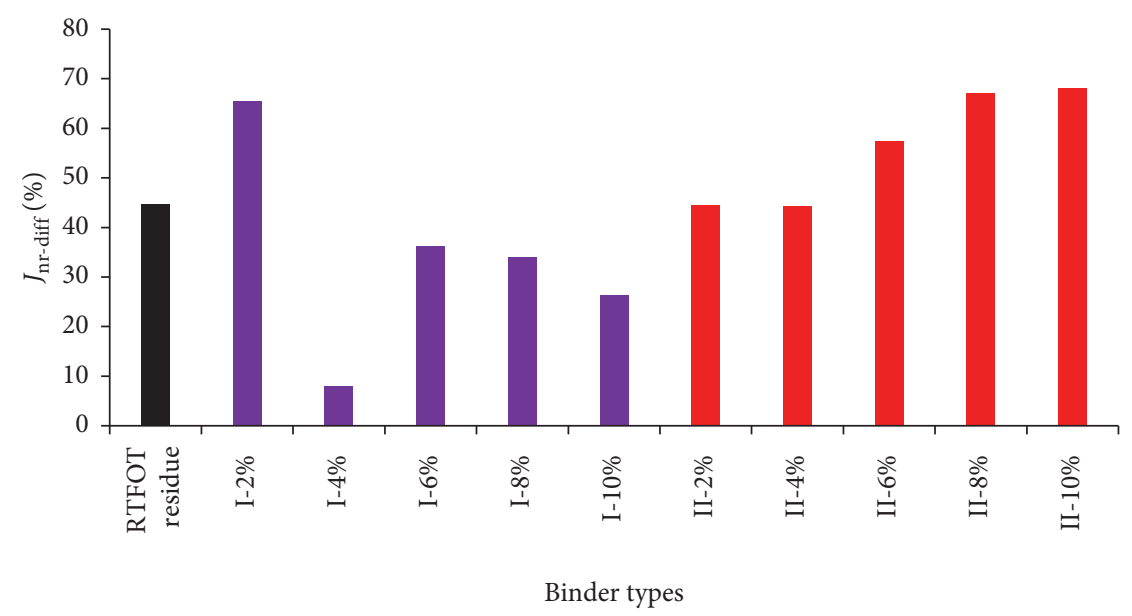

(c)

Figure 7: Effects of rejuvenators on the rutting parameters of the rejuvenated SBSMA. (a) Percent recovery (R); (b) nonrecoverable creep compliance $\left(\mathrm{J}_{\mathrm{nr}}\right)$; and $(\mathrm{c})$ stress sensitivity index $\left(\mathrm{J}_{\mathrm{nr}-\mathrm{diff}}\right)$.

The rheological behavior of asphalt binder was considered in the linear range at a stress level of $0.1 \mathrm{kPa}$. When the stress level rose to $3.2 \mathrm{kPa}$, the nonlinear rheological behavior of asphalt binder was closer to field conditions under a heavy traffic loading. The change in the rheological behavior under different stress levels revealed the stress sensitivity of asphalt binders, among others, as a function of temperature and loading.

As can be seen in Figure $7(\mathrm{c})$, the $J_{\text {nr-diff }}$ values of rejuvenated SBSMA were all less than the limiting value (75\%) recommended by AASHTO M332. With the change in the rejuvenator contents, the trends of the $J_{\text {nr-diff }}$ values for the two rejuvenators were different, with Type II exhibiting an almost linearly increasing trend. However, the stress sensitivity (the average of $J_{\text {nr-diff }}$ values) of Type II rejuvenator was about 1.6 times higher than that of Type I rejuvenator. Theoretically, the inference of these test results was that an asphalt pavement comprised of aged SBSMA that had been rejuvenated with Type I rejuvenator had improved durability and serviceability towards heavy traffic loading.

3.2.5. Fatigue Performance Based on the LAS Test. Fatigue $A$ and $B$ parameters of the rejuvenated SBSMA were obtained from the LAS test. With an increase in the rejuvenator content, Figure 8 shows an initial decrease in parameter $A$ to $8.96 \times 10^{5}$ (Type I) and $9.14 \times 10^{5}$ (Type II), respectively, and thereafter increased to $1.65 \times 10^{6}$ (Type I) and $1.24 \times 10^{6}$ (Type II). By contrast, the absolute value of parameter $B$ decreased gradually with an increase in the rejuvenator dosage. In general, parameter $A$ decreased with the decrease of the storage modulus in the loading process, indicating that the deformation resistance of asphalt binder decreased due to continuous cumulative damage during the loading cycles.

Fatigue parameter $B$ defines the quantitative measure of the stress and strain sensitivity of the asphalt binder. The higher the absolute value of parameter $B$ is, the greater the rate of fatigue life reduction of the asphalt binder is with an increase in the strain amplitude. Theoretically, asphalt binders with a higher value for parameter $A$ and lower absolute value for parameter $B$ infer to a longer fatigue life for the resultant asphalt mixture and pavement [38]. With increasing rejuvenator dosage, the rejuvenated SBSMA generally exhibited an increasing trend in fatigue performance as observed from the LAS. However, the rejuvenator dosage should be controlled up to an optimum level so as to avoid a counteractive effect that could potentially reduce the fatigue resistance of rejuvenated SBSMA.

The fatigue damage characteristic curves of the asphalt binders are shown in Figure 9. With an increase in the strain level above $15 \%$, the stress was exhibiting a decreasing trend under the critical repeated loading cycles, which indicated the potential occurrence of damage. The peak value of the shear stress was called the yield stress, and the corresponding peak shear strain was called the yield strain. From Figure 9, the further additions ( $2 \%$ to $10 \%)$ of the rejuvenators decreased the yield stress $(0.349 \mathrm{MPa}$ to $0.280 \mathrm{MPa}$ for Type I; $0.453 \mathrm{MPa}$ to $0.335 \mathrm{MPa}$ for Type II) and increased the yield strain (14.4\% to $15.8 \%$ for Type I; $13.5 \%$ to $16.4 \%$ for Type II), respectively, which indicated that the fatigue cracking resistance of the blends had improved as theoretically expected.

The medium-temperature rheological behavior of rejuvenated SBSMA depended significantly on the strain levels, the types, and contents of rejuvenators. In general, asphalt binders have a shorter fatigue life $\left(N_{\mathrm{f}}\right)$ at higher strain levels and vice versa [39]. For instance, Figure 10 indicates that if the strain level is halved, the fatigue life will, on average, increase by almost 8 times. With an increase in the rejuvenator dosage, there were two peak $N_{\mathrm{f}}$ values for each blend (124,166 and 110,681 cycles for Type I and 99,039 and 93,102 cycles for Type II at 2.5\% strain level, resp.); see Figure 10. Figure 10 further shows that the rejuvenated blends with rejuvenators I-4\%, I-10\%, II-2\%, and II-4\% have relatively longer fatigue lives. On average, the fatigue life of the 


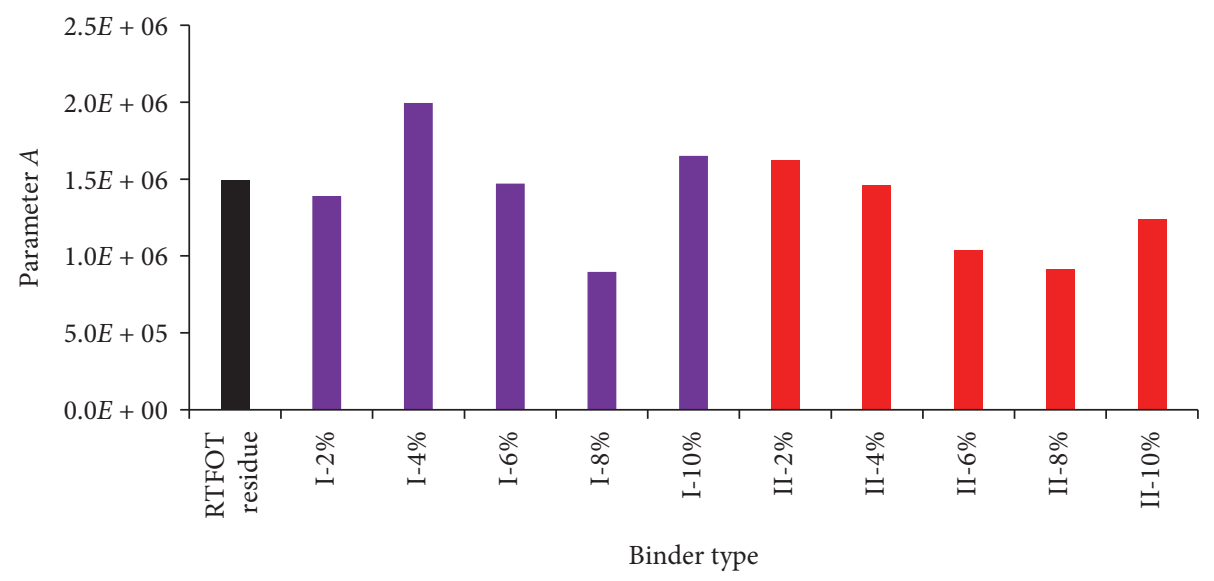

(a)

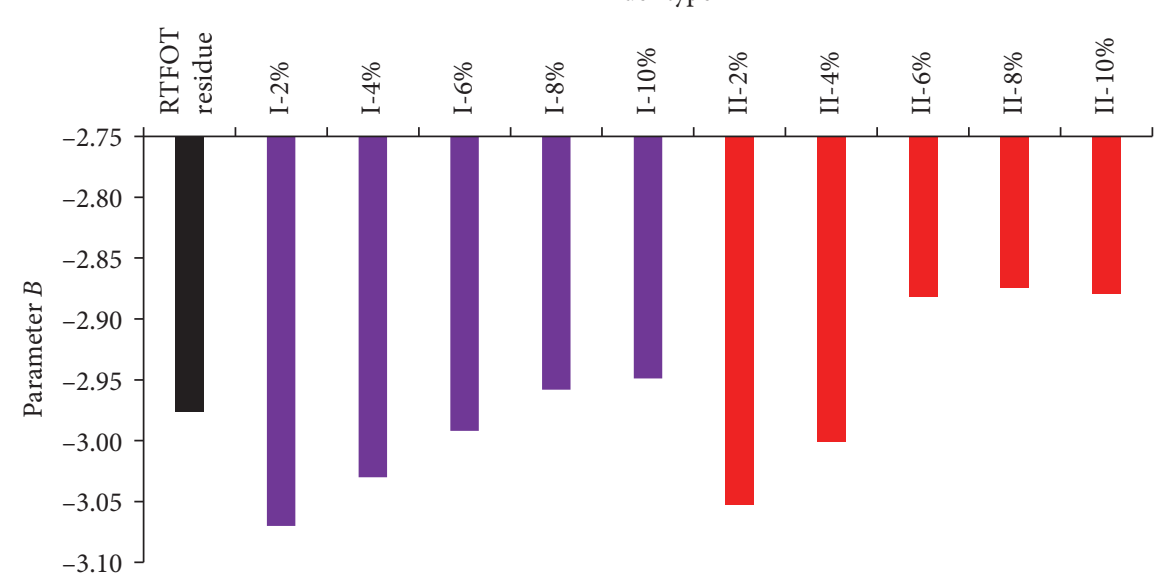

(b)

Figure 8: LAS test results. (a) Fatigue parameter A; (b) fatigue parameter B.
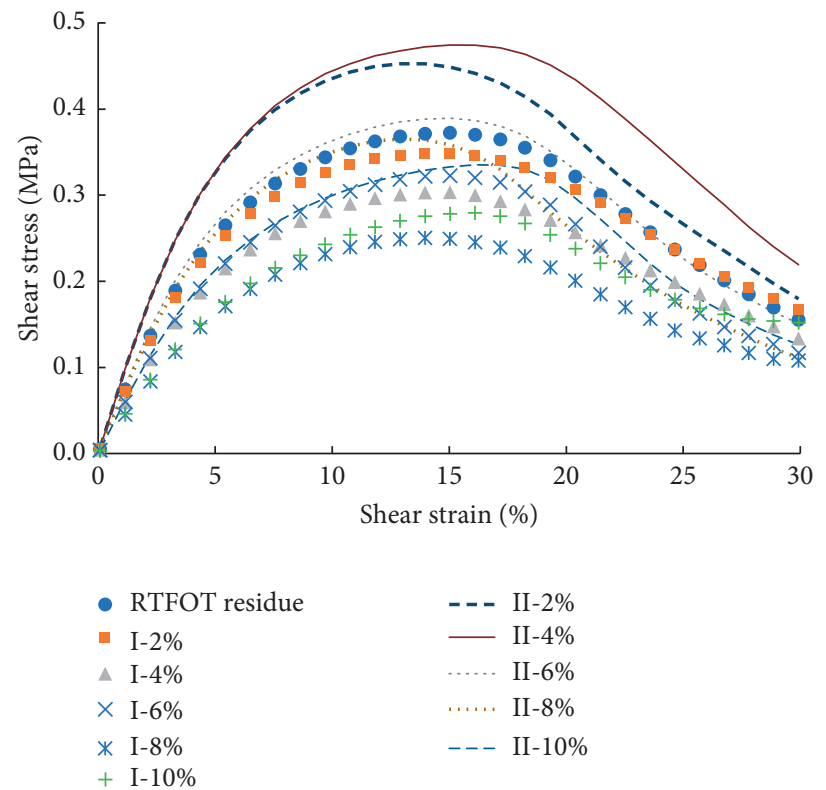

FIgURE 9: Stress-strain curves for the rejuvenated SBS-modified asphalt binders. 


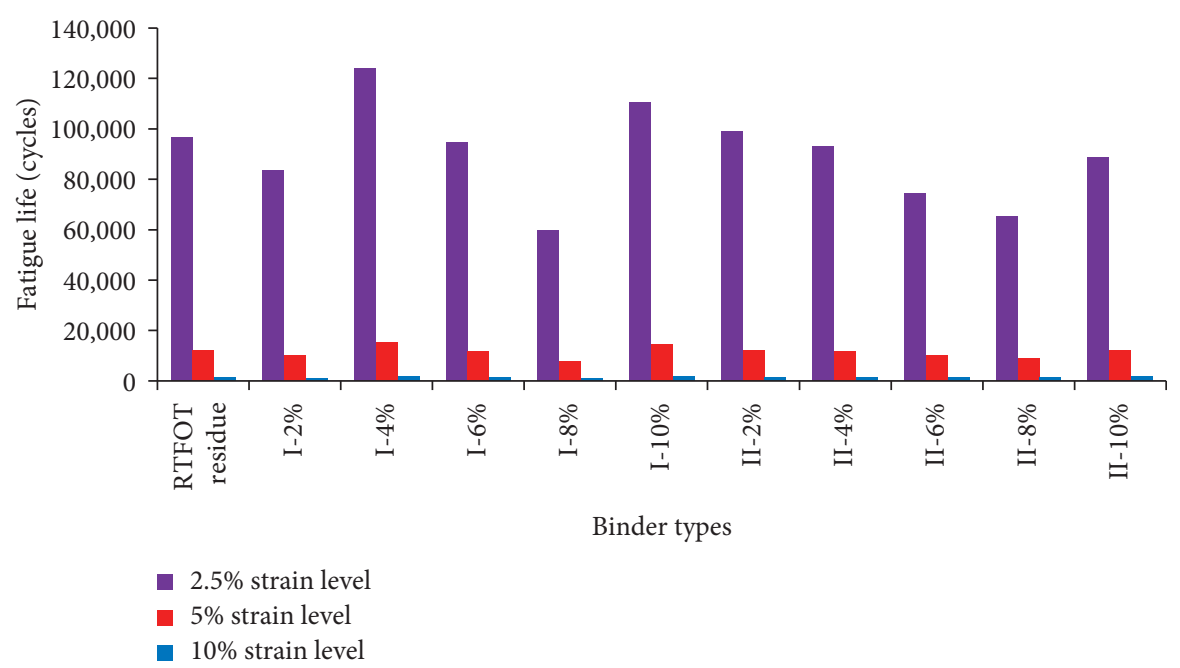

Figure 10: Effects of the rejuvenators and strain levels on fatigue life.

rejuvenated SBSMA with $4 \sim 10 \%$ rejuvenator Type I was about 1.21 times longer than that of the rejuvenator Type II. Overall, the rejuvenator Type I exhibited improved performance in terms of rejuvenating the fatigue damage resistance of the SBSMA.

\section{Conclusions and Recommendations}

This study investigated the effects of three types of rejuvenators, designated as Type I, Type II, and Type III, with varying dosages $(2 \%, 4 \%, 6 \%, 8 \%$, and $10 \%)$ and dosages increments $(0 \%, 2 \%, 4 \%$, and $6 \%)$ on the physical/rheological properties and performance characteristics (rutting, thermal, and fatigue cracking resistance) of the first and second rejuvenated SBSMA. From the study findings, the following conclusions and recommendations were drawn:

(1) Compared to the residues after RTFOT and PAV aging, the physical properties of the first and second rejuvenated SBSMA were improved and presented as the increases of the penetration and ductility and the decreases of the softening point of the asphalt blends. Among the three rejuvenators, the rejuvenation effect of Type I was the most excellent. The optimal rejuvenator dosage was $6 \sim 8 \%$ for the first rejuvenation, and the optimal rejuvenator dosage for the second rejuvenation was $10 \sim 12 \%$ (the increment of optimal rejuvenator dosage was $4 \%$ ).

(2) The rutting and cracking characteristics of the rejuvenated SBSMA were evaluated using DSR and BBR. The addition of rejuvenator to aged SBSMA was found to decrease the high-temperature rutting resistances $\left(G^{*} / \sin \delta\right)$ of the rejuvenated SBSMA. The rejuvenated SBSMA exhibited lower creep stiffness $(S(t))$ and a higher rate of relaxation $(m$ value) values compared to aged asphalt binder. It is expected that such improvement in relaxation properties of rejuvenated binders may enhance the low-temperature cracking resistances of rejuvenated pavements. The rejuvenator promoted asphalt binder durability by making delta $T_{c}\left(\Delta T_{c}\right)$ parameter less negative. Three types of rejuvenators could all enhance the physical and rheological properties of the aged SBSMA. The target Superpave PG of the rejuvenated SBSMA, PG 76-22, could be achieved with the additions of optimal dosages (6 8\%) of rejuvenator Type I.

(3) The additions of rejuvenators to the asphalt binder blends resulted in a reduction of the percent recovery ( $R$ value) and an increase in the nonrecoverable creep compliance ( $J_{\mathrm{nr}}$ value), indicating the positive effects of the rejuvenators on the high-temperature rutting resistance of rejuvenated SBSMA. The stress sensitivity $\left(J_{\text {nr-diff }}\right)$ of the asphalt binder blends with Type I rejuvenator was only $60 \%$ of that of Type II rejuvenator. Thus, asphalt mixtures and pavements using Type I rejuvenator were theoretically expected to exhibit more rutting resistance potentials under severe stress conditions.

(4) The fatigue life of rejuvenated SBSMA was found to significantly depend on the strain levels, rejuvenator type, and dosage, respectively. The addition of rejuvenators improved the elastic properties and correspondingly decreased the yield stresses of the rejuvenated SBS asphalt binders. The fatigue life of the asphalt binder blend with Type I rejuvenator was about $130 \%$ to that of Type II rejuvenator.

(5) The rutting and fatigue characteristics of the rejuvenated SBSMA were successfully evaluated using the MSCR and LAS tests, respectively. Based on these tests, rejuvenator Type I yielded the best rejuvenation/regeneration effects in terms of both the rheological properties and performance characteristics.

Overall, this study has shown that the use of rejuvenators has the potential to enhance the physicorheological properties and performance characteristics of aged SBSMA. For the materials evaluated and tests conducted in this study, rejuvenator Type I, with an optimum dosage of $6 \sim 8 \%$, was 
found to be the most excellent rejuvenator in terms of enhancing the physicorheological properties and performance characteristics (rutting, thermal, and fatigue cracking resistance) of aged SBSMA. Although limited to the specific materials evaluated in this paper, the study findings, evidently, provide a viable platform for further research into the rejuvenation of aged SBSMA including more laboratory testing, field validation, and practical applications.

\section{Data Availability}

The data used to support the findings of this study are included within the paper.

\section{Conflicts of Interest}

The authors declare that there are no conflicts of interest regarding the publication of this paper.

\section{Acknowledgments}

This work was supported by the Fundamental Research Funds for the Central Universities (Grant no. 3221009602), Kunshan Transportation Development Holding Group Co., Ltd. (Grant no. 8521002599), and the National Natural Science Foundation of China (Grant no. 51778140). The authors also greatly appreciate and gratefully acknowledge the sponsors' funding support. Special thanks and due gratitude also go to all those who helped during the course of this study.

\section{References}

[1] W. L. Ye, W. Jiang, J. H. Shan et al., "Research on molecular weight distribution and rheological properties of bitumen during short-term aging," Journal of Materials in Civil Engineering, vol. 32, no. 3, Article ID 04019377, 2020.

[2] Z. Leng, Z. F. Tan, H. Y. Yu, and J. Guo, "Improvement of storage stability of SBS-modified asphalt with nanoclay using a new mixing method," Road Materials and Pavement Design, vol. 20, no. 7, pp. 1601-1614, 2019.

[3] C. Z. Zhu, H. L. Zhang, D. M. Zhang, and Z. H. Chen, "Influence of base asphalt and SBS modifier on the weathering aging behaviors of SBS modified asphalt," Journal of Materials in Civil Engineering, vol. 30, no. 3, Article ID 04017306, 2018.

[4] S. P. Wu, Z. J. Zhao, Y. Xiao, M. W. Yi, Z. W. Chen, and M. L. Li, "Evaluation of mechanical properties and aging index of 10-year field aged asphalt materials," Construction and Building Materials, vol. 155, pp. 1158-1167, 2017.

[5] A. Behnood, "Application of rejuvenators to improve the rheological and mechanical properties of asphalt binders and mixtures: a review," Journal of Cleaner Production, vol. 231, pp. 171-182, 2019.

[6] A. Behnood and M. Modiri Gharehveran, "Morphology, rheology, and physical properties of polymer-modified asphalt binders," European Polymer Journal, vol. 112, pp. 766791, 2019.

[7] C. Q. Yan, W. D. Huang, J. M. Ma et al., "Characterizing the SBS polymer degradation within high content polymer modified asphalt using ATR-FTIR," Construction and Building Materials, vol. 233, Article ID 117708, 2020.
[8] M. S. Cortizo, D. O. Larsen, H. Bianchetto, and J. L. Alessandrini, "Effect of the thermal degradation of SBS copolymers during the ageing of modified asphalts," Polymer Degradation and Stability, vol. 86, no. 2, pp. 275-282, 2004.

[9] C. Q. Yan, F. P. Xiao, W. D. Huang, and Q. Lv, "Critical matters in using attenuated total reflectance fourier transform infrared to characterize the polymer degradation in styrenebutadiene-styrene-modified asphalt binders," Polymer Testing, vol. 70, pp. 289-296, 2018.

[10] C. W. Wei, H. H. Duan, H. L. Zhang, and Z. H. Chen, "Influence of SBS modifier on aging behaviors of SBSmodified asphalt," Journal of Materials in Civil Engineering, vol. 31, no. 9, Article ID 04019184, 2019.

[11] L. F. Walubita, G. S. Simate, and J. H. Oh, "Characterising the ductility and fatigue crack resistance potential of asphalt mixes based on the laboratory direct tensile strength test," Journal of the South African Institution of Civil Engineering, vol. 52, no. 2, pp. 31-40, 2010.

[12] L. F. Walubita, S. I. Lee, A. N. M. Faruk et al., "Texas flexible pavements and overlays: year 5 report-complete data documentation," Report No. FHWA/TX-15/0-6658-3, Texas A\&M Transportation Institute (TTI), College Station, TX, USA, 2017.

[13] D. Q. Sun, G. Q. Sun, X. Y. Zhu et al., “A comprehensive review on self-healing of asphalt materials: mechanism, model, characterization and enhancement," Advances in Colloid and Interface Science, vol. 256, pp. 65-93, 2018.

[14] J. T. Lin, J. H. Hong, C. Huang, J. P. Liu, and S. P. Wu, "Effectiveness of rejuvenator seal materials on performance of asphalt pavement," Construction and Building Materials, vol. 55, pp. 63-68, 2014.

[15] H. Liu, "Research on preventive maintenance technology of asphalt pavement based on penetrating regeneration," Master's Thesis, Southeast University, Nanjing, China, 2019. in chinese

[16] M. Guo, Y. Q. Tan, D. S. Luo et al., "Effect of recycling agents on rheological and micromechanical properties of SBSmodified asphalt binders," Advances in Materials Science and Engineering, vol. 2018, Article ID 5482368, 12 pages, 2018.

[17] I. Boz and M. Solaimanian, "Investigating the effect of rejuvenators on low-temperature properties of recycled asphalt using impact resonance test," International Journal of Pavement Engineering, vol. 19, no. 11, pp. 1007-1016, 2018.

[18] Z. Zhou, X. Y. Gu, Q. Dong, F. J. Ni, and Y. X. Jiang, "Rutting and fatigue cracking performance of SBS-RAP blended binders with a rejuvenator," Construction and Building Materials, vol. 203, pp. 294-303, 2019.

[19] A. F. Espinoza-Luque, I. L. Al-Qadi, and H. Ozer, "Optimizing rejuvenator content in asphalt concrete to enhance its durability," Construction and Building Materials, vol. 179, pp. 642-648, 2018.

[20] T. Koudelka, P. Coufalik, J. Fiedler, I. Coufalikova, M. Varaus, and F. Yin, "Rheological evaluation of asphalt blends at multiple rejuvenation and aging cycles," Road Materials and Pavement Design, vol. 20, no. sup1, pp. S3-S18, 2019.

[21] M. Elkashef, R. C. Williams, and E. Cochran, "Effect of asphalt binder grade and source on the extent of rheological changes in rejuvenated binders," Journal of Materials in Civil Engineering, vol. 30, no. 12, Article ID 04018319, 2018.

[22] J. A. Shen, S. N. Amirkhanian, and S.-J. Lee, "HP-GPC characterization of rejuvenated aged CRM binders," Journal of Materials in Civil Engineering, vol. 19, no. 6, pp. 515-522, 2007. 
[23] M. Zaumanis, R. B. Mallick, L. Poulikakos, and R. Frank, "Influence of six rejuvenators on the performance properties of reclaimed asphalt pavement (RAP) binder and 100\% recycled asphalt mixtures," Construction and Building $\mathrm{Ma}$ terials, vol. 71, pp. 538-550, 2014.

[24] B. Y. Cui, X. Y. Gu, D. L. Hu, and Q. Dong, "A multiphysics evaluation of the rejuvenator effects on aged asphalt using molecular dynamics simulations," Journal of Cleaner Production, vol. 259, Article ID 120629, 2020.

[25] E. Fini, A. I. Rajib, D. Oldham, A. Samieadel, and S. Hosseinnezhad, "Role of chemical composition of recycling agents in their interactions with oxidized asphaltene molecules," Journal of Materials in Civil Engineering, vol. 32, no. 9, Article ID 04020268, 2020.

[26] G. J. Xu, H. Wang, and W. Sun, "Molecular dynamics study of rejuvenator effect on RAP binder: diffusion behavior and molecular structure," Construction and Building Materials, vol. 158, pp. 1046-1054, 2018.

[27] V. Radhakrishnan, M. Ramya Sri, and K. Sudhakar Reddy, "Evaluation of asphalt binder rutting parameters," Construction and Building Materials, vol. 173, pp. 298-307, 2018.

[28] H. U. Bahia, D. I. Hanson, M. Zeng et al., "Characterization of modified asphalt binders in superpave mix design," NCHRP Report 459, Transportation Research Board, Washington, DC, USA, 2001.

[29] J. D’Angelo, R. Kluttz, R. N. Dongre, K. Stephens, and L. Zanzotto, "Revision of the superpave high temperature binder specification: the multiple stress creep recovery test (with discussion)," Journal of the Association of Asphalt Paving Technologists, vol. 76, pp. 123-162, 2007.

[30] Q. L. Yang, Q. Liu, J. Zhong, B. Hong, D. W. Wang, and M. Oeser, "Rheological and micro-structural characterization of bitumen modified with carbon nanomaterials," Construction and Building Materials, vol. 201, pp. 580-589, 2019.

[31] A. Behnood, A. Shah, R. S. McDaniel, M. Beeson, and J. Olek, "High-temperature properties of asphalt binders: comparison of multiple stress creep recovery and performance grading systems," Transportation Research Record: Journal of the Transportation Research Board, vol. 2574, no. 1, pp. 131-143, 2016.

[32] C. M. Johnson, H. U. Bahia, and H. Wen, "Evaluation of strain-controlled asphalt binder fatigue testing in the dynamic shear rheometer," in Proceedings of the 4th International SIIV Congress, Palermo, Italy, 2007.

[33] J. M. Yu, Y. F. Guo, L. Peng, F. Guo, and H. Y. Yu, "Rejuvenating effect of soft bitumen, liquid surfactant, and biorejuvenator on artificial aged asphalt," Construction and Building Materials, vol. 254, Article ID 119336, 2020.

[34] R. Micaelo, A. Pereira, L. Quaresma, and M. T. Cidade, "Fatigue resistance of asphalt binders: assessment of the analysis methods in strain-controlled tests," Construction and Building Materials, vol. 98, pp. 703-712, 2015.

[35] R. M. Anderson, G. N. King, D. I. Hanson, and P. B. Blankenship, "Evaluation of the relationship between asphalt binder properties and non-load related cracking," Journal of the Association of Asphalt Paving Technologists, vol. 80, pp. 615-664, 2011.

[36] A. I. Rajib, F. Pahlavan, and E. H. Fini, "Investigating molecular-level factors that affect the durability of restored aged asphalt binder," Journal of Cleaner Production, vol. 270, Article ID 122501, 2020.

[37] X. J. Li, N. Gibson, A. Andriescu, and T. S. Arnold, "Performance evaluation of REOB-modified asphalt binders and mixtures," Road Materials and Pavement Design, vol. 18, no. sup1, pp. 128-153, 2017.

[38] P. K. Ashish, D. Singh, and S. Bohm, "Investigation on influence of nanoclay addition on rheological performance of asphalt binder," Road Materials and Pavement Design, vol. 18, no. 5, pp. 1007-1026, 2017.

[39] L. F. Walubita, "Comparison of fatigue analysis approaches for predicting fatigue lives of hot-mix asphalt concrete (HMAC) mixtures," Texas A\&M University, College Station, TX, USA, Ph.D. Diss, 2006. 